\title{
Gut Microbiome of Healthy and Arthritic Dogs
}

\author{
Michela Cintio $₫$, Elisa Scarsella ${ }^{\circledR}$, Sandy Sgorlon, Misa Sandri and Bruno Stefanon *®D \\ Department of Agriculture, Food, Environmental and Animal Science, University of Udine, 33100 Udine, Italy; \\ michela.cintio@uniud.it (M.C.); scarsella.elisa@spes.uniud.it (E.S.); sandy.sgorlon@uniud.it (S.S.); \\ misa.sandri@uniud.it (M.S.) \\ * Correspondence: bruno.stefanon@uniud.it; Tel.: +39-0432-55-8581
}

Received: 30 May 2020; Accepted: 11 July 2020; Published: 14 July 2020

\begin{abstract}
Several studies have underlined the interplay among host-microbiome and pathophysiological conditions of animals. Research has also focused specifically on whether and how changes in the gut microbiome have provoked the occurrence of pathological phenomena affecting cartilage and joints in humans and in laboratory animals. Here, we tried to evaluate the relationship between the gut microbiome and the hip and elbow arthritis in owned dogs. The study included 14 dogs suffering from chronic arthritis (AD) and 13 healthy dogs (HD). After the first visit and during the period of the study, the dogs, under the supervision of the owner, were fed a semi-moist complete diet supplemented with omega 3 fatty acids. Feces and blood samples were collected in the clinic at the first visit (T0) and after days (T45). The plasma C-reactive protein (CRP) was higher, and the serum vitamin B12 and folate concentrations were lower $(p<0.05)$ in the AD group in comparison to the HD group. Data of the fecal microbiome showed that the relative abundances of the genus Megamonas were higher in $\mathrm{AD}(p<0.001)$, while the relative abundance of the families Paraprevotellaceae, Porphyromonadaceae, and Mogibacteriaceae was significantly lower in comparison to HD. The results of the study identified several bacterial groups that differed significantly in the fecal microbiome between healthy and diseased dogs. If the observed differences in fecal bacterial composition predispose dogs to hip and elbow arthritis or if these differences reflect a correlation with these conditions deserves further investigation.
\end{abstract}

Keywords: gut microbiome; hematological parameters; arthritis; dogs

\section{Introduction}

In the last decade, several studies have focused on the gut microbiome in dogs and on the relationship that inflammatory bowel diseases and intestinal dysbiosis have with pathological conditions of the organism [1,2]. It has been also demonstrated, both in human and animal models, that the microorganism inhabitants of the gut and the compounds they produce, such as short-chain fatty acids, lactic acid, and metabolites of amino acids, affect host physiology [3]. Among the others, the microbial metabolism of tryptophan and threonine and the related interaction with the availability of neurotransmitters for the host has led to the development of the brain-gut-microbiome axis concept $[4,5]$. It has also been reported that the microbiome can influence distant organs by three principal effects, regulating the nutritional absorption and production of vitamins, regulating the immune system, and translocating bacteria through the endothelial barrier and into the bloodstream [6]. This has been investigated in human and laboratory animals [7-10], but scientific pieces of evidence are still lacking for dogs.

Recent studies have brought to light a possible new interplay of the gut microbiome with pathological conditions other than inflammatory bowel diseases, such as metabolic syndrome and joint damage, the latter caused by chronic low-grade systemic inflammation [3]. It is already accepted that 
when intestinal dysbiosis occurs, the whole organism suffers from several metabolic and inflammatory diseases, and in this context, it is conceivable to assume that also the pathogenesis of the joint disease could be related to it.

According to Tomasello et al. (2014) [11], in humans affected by irritable bowel syndrome, it was observed that during microbial dysbiosis, an immune system dysregulation could occur, which consequently brought to a local inflammatory state. Hernandez et al. (2018) [6] reported that during dysbiosis, a leaky gut could happen, and this allowed a transfer of gut microbes from the intestinal lumen to other sites of the body (e.g., mammary gland; [12]) through dendritic cells (DCs) and macrophages. If this crossing is implicated in the onset of joint disease is a hypothesis that deserves further investigation.

Osteoarthritis is a chronic disease that in the long run leads to a degradation of cartilage and bone, abnormal growth of bone tissue (osteophytes), and inflammation of the synovial membrane (synovitis), causing arthrosis and pain, stiffness, and loss of functionality of the joints [13-15]. This pathology is multifactorial and is mainly related to genetic predisposition, mechanical events, age, sex, lifestyle, poor body condition, and excess body weight [3].

A common feature of arthrosis is local and sometimes systemic inflammation, but, until now, the gut-joint axis has only been hypothesized in human and laboratory animals [9-16], considering that clinical evidence linking gut microbiome with arthritis is still lacking. In this study, we evaluated hematological parameters, fecal microbiome composition, and end products of fermentation in healthy and arthritic dogs with the aim to evaluate a relationship, if any, supporting the microbiome-joint axis in dogs.

\section{Materials and Methods}

\subsection{Animals and Housing}

For the purpose of the study, 13 healthy dogs (HD) and 14 dogs with hip or elbow arthritis (AD) were enrolled from a veterinary local clinic. AD dogs had a history of chronic arthritis and were not under NSAIDs (non-steroidal anti-inflammatory drugs) or steroidal treatments since the last month. Arthritis was diagnosed by the veterinarians on the basis of clinical anamnesis for limping forelimbs and/or associated with posterior limping; rapid fatigue after effort; decrease in motor activity; radiographic evidence of osteoarthritis (AD) in one or two joints (elbow, hips). Dogs were of both sex and different breeds, including crossbreeds, were older than 18 months, and weighed more than $10 \mathrm{~kg}$ and less than $40 \mathrm{~kg}$. Details of the dogs are reported in Supplementary Table S1. After the visit, $\mathrm{HD}$ and $\mathrm{AD}$ dogs were fed a semi-moist complete diet (N.P. Industries, Udine, Italy). The diet consisted of the diced potato $(4.0 \%)$, potato starch $(4.0 \%)$, chicken $(17.8 \%)$, swine heart $(17.0 \%)$, swine lung $(10.0 \%)$, swine liver $(7.4 \%)$, vitamins and minerals $(1.25 \%)$, additives (thickeners, gelling agents; $1.8 \%$ ), vegetable oil $(1.25 \%)$, prebiotic (xylooligosaccharides, $0.01 \%)$, and oregano essential oil $(0.0006 \%)$. Diet contained $80.0 \%$ of water, $7.2 \%$ of crude protein, $5.4 \%$ of lipids, $0.45 \%$ of crude fiber, $2.1 \%$ of ash, and $3.3 \%$ of starch. Lipids contained $5.3 \%$ of omega 3 (alpha-linolenic $3.7 \%$, eicosapentaenoic $0.5 \%$, and docosahexaenoic $0.3 \%$ ). The diet was formulated to provide omega 3 fatty acids to support the metabolism of joints in the case of osteoarthritis. Throughout the period of study, dogs were housed in the usual home and condition and were followed by the owners, and informed consent was obtained from the owners of the dogs recruited for the study. All protocols, procedures, and the care of the animals complied with the Italian legislation on animal care and were approved by the ethical committee of the University of Udine (26/08/2019; protocol n. 7/2019).

\subsection{Collection of Samples}

The samples from HD were collected according to a scheduled check agreed with the owners, and for the $\mathrm{AD}$, the samples were collected according to the veterinary opinion to monitor their clinical conditions. Blood samples were withdrawn at the first clinical examination (T0) and after 45 days (T45) 
from the beginning of the trial in the veterinary clinic. Fecal samples were also collected at T0 and T45 from the first evacuation of the morning by the owners, and the specimens were immediately frozen at $-20^{\circ} \mathrm{C}$. Samples were delivered to the clinic and transported to the laboratory within 1 week and stored at $-80^{\circ} \mathrm{C}$. For the analyses, the inner part of the stools was sampled for analysis.

\subsection{Hematological Analysis}

Blood samples were collected at the veterinary clinic in Li-heparin tubes (Terumo Europe N.V., Leuven, Belgium) and without anticoagulant tubes and then centrifuged at 3000 RPM for 20 min. Plasma and serum were transferred in $5 \mathrm{~mL}$ vials and immediately frozen at $-20^{\circ} \mathrm{C}$. The samples were sent within 3 days to an external certified veterinary laboratory for a complete biochemical analysis of plasma, folate, vitamin B12, and trypsin-like immunoreactivity (TLI) in serum (Vetlab, Padova, Italy).

\subsection{Fecal Short-Chain Fatty Acid and Lactic Acid Analysis}

Lactic acid and short-chain fatty acids (SCFAs) (acetic, propionic, butyric, isobutyric, and isovaleric) were analyzed by HPLC [17], starting from $1 \mathrm{~g}$ of feces, which was diluted with $50 \mathrm{~mL}$ of $0.1 \mathrm{~N} \mathrm{H}_{2} \mathrm{SO}_{4}$ aqueous solution and homogenized for $15 \mathrm{~min}$ by a mechanical stirrer (Instruments Srl, Milano, Italy). After centrifugation at $20,000 \times g$ for $20 \mathrm{~min}$ at $4{ }^{\circ} \mathrm{C}$ to separate the liquid phase from the solid residuals, the supernatant was filtered with a $0.45 \mu \mathrm{m}$ syringe filter of polypore (Alltech, Casalecchio di Reno, $\mathrm{BO}$, Italy). An aliquot of $20 \mu \mathrm{L}$ of the resulting sample was injected in the HPLC equipped with an Aminex HPX-87H (Bio-Rad, Hercules, CA, USA) ion exclusion column (300 mm $\times 7.8 \mathrm{~mm}, 9 \mu \mathrm{m})$ and a pre-column (Bio-Rad, Hercules, CA, USA) kept at $40^{\circ} \mathrm{C}$. The isocratic elution flux was $0.6 \mathrm{~mL} / \mathrm{min}$, using $0.008 \mathrm{~N} \mathrm{H}_{2} \mathrm{SO}_{4}$ solution as a mobile phase, and the detection length was $220 \mathrm{~nm}$. SCFAs and lactic acid concentrations were calculated with reference to a standard solution of $4.50 \mathrm{mg} / \mathrm{mL}$ of lactic acid, $5.40 \mathrm{mg} / \mathrm{mL}$ of acetic acid, $5.76 \mathrm{mg} / \mathrm{mL}$ of propionic acid, $7.02 \mathrm{mg} / \mathrm{mL}$ of butyric acid and isobutyric acid and isovaleric acid in $0.1 \mathrm{~N} \mathrm{H}_{2} \mathrm{SO}_{4}$ (Sigma-Aldrich ${ }^{\circledR}$ Co., Milano, Italy). Quantifications were calculated using an external calibration curve based on these standards. Each acid was expressed as a molar percentage of the sum of SCFAs and lactic acid (TA).

\subsection{Fecal DNA Extraction, Sequencing, and Taxonomic Annotation}

Microbial DNA from the inner part of the stool was extracted from $150 \mathrm{mg}$ of starting material using a Fecal DNA MiniPrep kit (Zymo Research; Irvine, CA, USA), following the manufacturer's instruction, including a bead-beating step. DNA concentration was measured with a QubitTM 3 Fluorometer (Thermo Scientific; Waltham, MA, USA). The DNA was fragmented, and the 16S rRNA of V3 and V4 regions amplified for library preparation, adding also the indexes for sequencing, using a Nextera DNA Library Prep kit (Illumina; San Diego, CA, USA), with the primers suggested by Klindworth et al. (2016) [18]. The amplicons were sequenced with a MiSeq (Illumina; San Diego, CA, USA) in $2 \times 300$ paired-end mode.

The Quantitative Insights Into Microbial Ecology (QIIME 2) [19] was used to process the raw sequences, which were uploaded to the NCBI Sequence Read Archive (BioProject ID PRJNA611632). After demultiplexing, reads passing with Phred score $\geq 30$ were annotated for $16 S$ rRNA against the Greengenes database (version gg.13_8.otus.tar.gz), with 99\% identify with reference sequences. Chimeras were also detected and then filtered from the reads, and the remaining sequences were clustered into operational taxonomic units (OTUs) by using an open reference approach in QIIME 2.

\subsection{Statistical Analysis}

Between samples, the minimum number of reads count was 10,578 , and average reads were $36,395 \pm 11,284$ and $31,287 \pm 16,035$ for AD and HD groups, respectively $(p>0.05)$. The 16S rRNA annotated sequences were then normalized to \%o abundance profiles for each sample and each taxonomic level, already known as relative abundance (RA). Taxa with RA lower than 10\%o were excluded from the statistical analysis [5-20]. 
Before statistical analysis, normality of distribution of the independent variables (SCFAs, lactic acid, and hematological parameters) was checked with the non-parametric Kolmogorov-Smirnoff test. When data were not normally distributed, a natural logarithmic transformation was used. Data were then rechecked and resulted normally distributed. The linear mixed model was used to analyze all these variables. The model included the fixed effect of time of sampling (2 levels, T0 and T45), status (2 levels AD, HD), and the interaction of time of sampling with status, with the subject (dog) as random factor repeated over the time of sampling. Bonferroni multiple testing correction was used as a significance test. For the microbiome, Shannon and Evenness diversity indices were calculated at the family and genus levels [17]. Beta diversity was assessed with the Brian Curtis dissimilarity matrix and visualized using principal coordinate analysis (PCoA) plot. Analysis of similarity (ANOSIM) was performed with the 'Vegan' package in $\mathrm{R}$ (Version 3.2.1) to test whether the microbiome significantly differed between $\mathrm{AD}$ and HD at T0 and T45. All these analyses were performed with XLSTAT [21]. A linear discriminant analysis (LDA) effect size (LEfSe) was applied to detect taxa that differed between diseased and healthy groups at T0 and T45 [22].

\section{Results}

Statistical analyses of plasma biochemistry results are depicted in Table 1. C-reactive protein $(\mathrm{CRP})$, urea, albumin, and lipase were significantly higher in $\mathrm{AD}(p<0.05)$ in comparison to HD. Creatine showed an increase with time of sampling $(p<0.05)$ in both dog groups, while for total bilirubin, a negative variation at T45 compared to T0 $(p<0.05)$ was registered. Besides, this latter parameter was higher in $\mathrm{HD}$ than $\mathrm{AD}(0.19$ and 0.16 , respectively; $p<0.05)$. Cholesterol underwent positive variation for the effect of time and was higher in AD than in $\operatorname{HD}(p<0.05)$. There was a significant increase in alanine transaminase (ALT/GTP) in AD $(p<0.05)$, but it decreased with time $(p<0.001)$, while for aspartate transaminase (AST/GOT), a decrease from T0 to T45 was reported $(p<0.001)$. Alkaline phosphatase (ALP) significantly decreased from T0 to T45 $(p<0.05)$, being lower in $\mathrm{HD}$, similar to the creatine kinase (CK) $(p<0.05)$. Gamma-glutamyl transferase (GGT) was higher at T45 ( $p<0.05)$ compared to T0. Regarding the mineral concentrations in plasma, the analysis showed a slight increment of $\mathrm{Ca}$ and $\mathrm{Cl}$ for the effect of time $(p<0.001)$, while $\mathrm{K}$ and $\mathrm{Mg}$ were statistically higher in $\mathrm{HD}$ than $\mathrm{AD}(p<0.05)$. Inorganic $\mathrm{P}$ registered a variation for the interaction time $\mathrm{X}$ status $(p<0.05)$. $\mathrm{Na}$ increased from T0 to T45 ( $p<0.001)$, being significantly higher in HD $(p<0.05)$. Finally, the plasma concentrations of vitamin B12 and folates were significantly higher in AD $(p<0.05)$ in comparison to HD.

Table 1. Mean concentrations of the parameters determined by blood biochemistry in healthy (HD) and diseased (AD) dogs at the beginning of the study (T0) and after 45 days (T45).

\begin{tabular}{|c|c|c|c|c|c|c|c|c|c|}
\hline \multirow{2}{*}{ Item } & \multirow{2}{*}{ Unit } & \multicolumn{2}{|c|}{ T0 } & \multicolumn{2}{|c|}{$\mathrm{T} 45$} & \multicolumn{2}{|c|}{ SEM } & \multicolumn{2}{|c|}{ Effects } \\
\hline & & AD & HD & AD & HD & & Time & Status & $T \times S$ \\
\hline Glucose & $\mathrm{mg} / \mathrm{dL}$ & 93.14 & 94.23 & 92.86 & 95.77 & 1.20 & NS & NS & NS \\
\hline Fructosamine & $\mathrm{umol} / \mathrm{L}$ & 204.93 & 191.23 & 215.21 & 219.77 & 5.14 & NS & NS & NS \\
\hline Urea & $\mathrm{mg} / \mathrm{dL}$ & 35.50 & 36.28 & 36.71 & 35.08 & 1.38 & NS & $*$ & NS \\
\hline Creatine & $\mathrm{mg} / \mathrm{dL}$ & 1.28 & 1.13 & 1.42 & 1.36 & 0.04 & $*$ & NS & NS \\
\hline Total bilirubin & $\mathrm{mg} / \mathrm{dL}$ & 0.20 & 0.26 & 0.16 & 0.19 & 0.01 & * & $*$ & NS \\
\hline Total proteins & $\mathrm{g} / \mathrm{dL}$ & 6.84 & 6.85 & 6.91 & 6.92 & 0.05 & NS & NS & NS \\
\hline Albumin & $\mathrm{g} / \mathrm{dL}$ & 3.04 & 2.98 & 3.01 & 2.91 & 0.04 & NS & $*$ & NS \\
\hline Globulin & $\mathrm{g} / \mathrm{dL}$ & 3.81 & 3.87 & 3.90 & 4.02 & 0.06 & NS & NS & NS \\
\hline Albumin/Globulin & $\mathrm{g} / \mathrm{dL}$ & 0.81 & 0.78 & 0.77 & 0.74 & 0.02 & NS & NS & NS \\
\hline Cholesterol & $\mathrm{mg} / \mathrm{dL}$ & 238.29 & 228.31 & 266.57 & 242.15 & 7.07 & NS & NS & $*$ \\
\hline Triglycerides & $\mathrm{mg} / \mathrm{dL}$ & 63.29 & 68.23 & 53.14 & 58.46 & 3.28 & NS & NS & NS \\
\hline Lipase & $\mathrm{u} / \mathrm{L}$ & 118.43 & 86.92 & 88.57 & 64.23 & 8.39 & NS & $*$ & NS \\
\hline C-Reactive Protein & $\mathrm{mg} / \mathrm{dL}$ & 0.41 & 0.15 & 0.33 & 0.12 & 0.03 & NS & $*$ & NS \\
\hline$\alpha$-Amylase & $\mathrm{u} / \mathrm{L}$ & 819.71 & 771.77 & 727.07 & 767.92 & 34.51 & NS & NS & NS \\
\hline AST (GOT) & $\mathrm{u} / \mathrm{L}$ & 30.79 & 32.23 & 21.64 & 25.08 & 0.99 & $* *$ & NS & NS \\
\hline ALT (GPT) & $\mathrm{u} / \mathrm{L}$ & 56.29 & 29.31 & 31.86 & 22.46 & 2.69 & $* *$ & * & * \\
\hline
\end{tabular}


Table 1. Cont.

\begin{tabular}{|c|c|c|c|c|c|c|c|c|c|}
\hline Item & Unit & \multicolumn{2}{|c|}{ T0 } & \multicolumn{2}{|c|}{ T45 } & \multicolumn{2}{|c|}{ SEM } & \multicolumn{2}{|c|}{ Effects } \\
\hline ALP & $\mathrm{u} / \mathrm{L}$ & 59.57 & 69.62 & 52.14 & 46.69 & 3.15 & * & NS & NS \\
\hline GGT & $\mathrm{u} / \mathrm{L}$ & 6.93 & 6.46 & 7.07 & 7.46 & 0.20 & $*$ & NS & * \\
\hline CK & $\mathrm{u} / \mathrm{L}$ & 102.43 & 158.92 & 90.29 & 97.69 & 8.82 & NS & NS & NS \\
\hline $\mathrm{LDH}$ & $\mathrm{u} / \mathrm{L}$ & 42.36 & 67.37 & 52.50 & 59.46 & 6.28 & NS & NS & NS \\
\hline $\mathrm{Ca}$ & $\mathrm{mg} / \mathrm{dL}$ & 10.14 & 10.02 & 10.91 & 10.44 & 0.10 & $* *$ & NS & NS \\
\hline P-in & $\mathrm{mg} / \mathrm{dL}$ & 3.49 & 5.03 & 3.89 & 3.98 & 0.16 & NS & NS & $*$ \\
\hline $\mathrm{Mg}$ & $\mathrm{mg} / \mathrm{dL}$ & 2.25 & 2.32 & 2.18 & 2.39 & 0.03 & NS & * & NS \\
\hline $\mathrm{Fe}$ & $\mu \mathrm{g} / \mathrm{dL}$ & 154.79 & 175.69 & 148.07 & 188.54 & 7.70 & NS & NS & NS \\
\hline $\mathrm{Cl}$ & $\mathrm{mEq} / \mathrm{L}$ & 109.64 & 109.11 & 111.07 & 110.53 & 0.52 & $*$ & NS & NS \\
\hline Vitamin B12 & $\mathrm{pg} / \mathrm{mL}$ & 326.64 & 500.69 & 360.79 & 451.46 & 29.07 & NS & * & NS \\
\hline
\end{tabular}

SEM: standard error of the means; AST (GOT): aspartate transaminase; ALT (GPT): alanine transaminase; ALP: alkaline phosphatase; GGT: gamma-glutamyl transferase; CK: creatinine kinase; LDH: lactate dehydrogenase; P-in: inorganic P; TLI: trypsin-like immunoreactivity. ${ }^{*} p<0.05 ;{ }^{* *} p<0.001$; NS: not significant.

The concentrations and the molar proportion (\%) of the SCFAs and lactic acid are reported in Supplementary Table S2. The molar concentrations of SCFAs and TA were not significant for any effect. Lactate and isovalerate showed a numerical increase in diseased subjects. The molar proportion of acetate showed a decrease $(p<0.05)$ at T45 compared to T0 in all the groups, while the molar proportion of butyrate was higher in $\mathrm{AD}$ in comparison to $\mathrm{HD}(7.7 \% \mathrm{vs} .7 .0 \%, p<0.05)$. No significant variation was registered for the other SCFAs.

Shannon index of diversity $\left(\mathrm{H}^{\prime}\right)$ and Evenness index $\left(\mathrm{J}^{\prime}\right)$ of the fecal microbiome significantly differed between AD and HD at the family level but not at the genus level (Figure 1).

The principal coordinate analyses (PCOA) was used to visualize beta diversity (Figure 2) between groups. The ANOSIM computed for the two times of sampling was significantly different at the family level $(p<0.01)$ between the two groups of dogs.

The differences in taxonomical terms between the two groups are depicted in Figure 3 . The bacterial taxa that were significantly increased in HD dogs were the families Paraprevotellaceae, Porphyromonadaceae, and Mogibacteriaceae and the genera Parabacteroides, Phascolarctobacterium, and p_75_a5. Even the family Peptococcaceae and its genus Peptococcus together with the family Succinivibrionaceae and its genus Anaerobiospirillum were significantly higher in HD. Indeed, the genus Megamonas showed a significantly higher relative abundance in AD. 


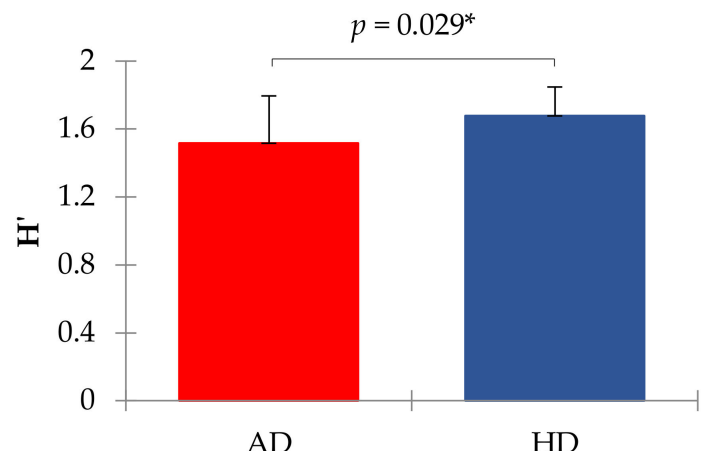

AD

HD

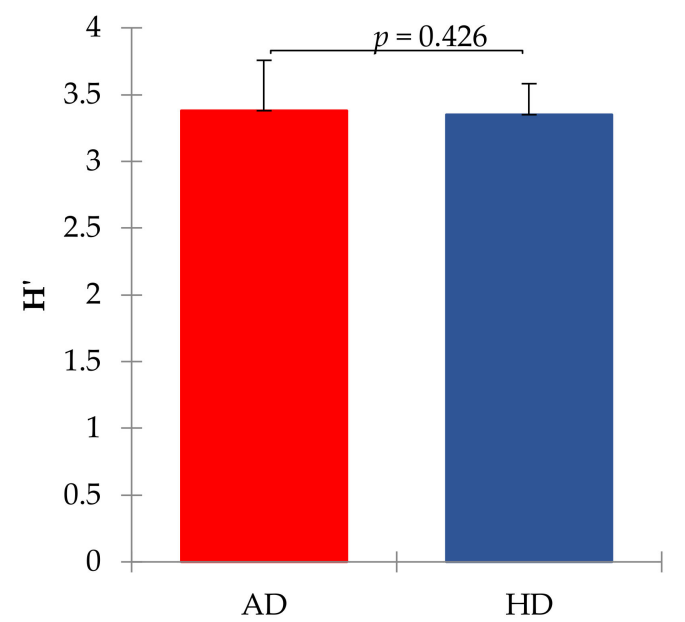

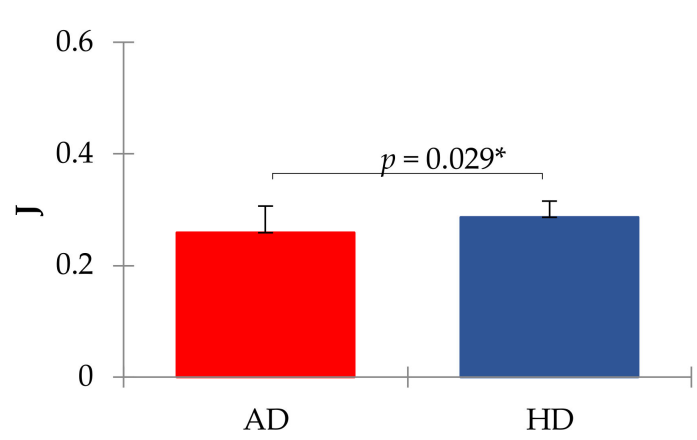

(A)

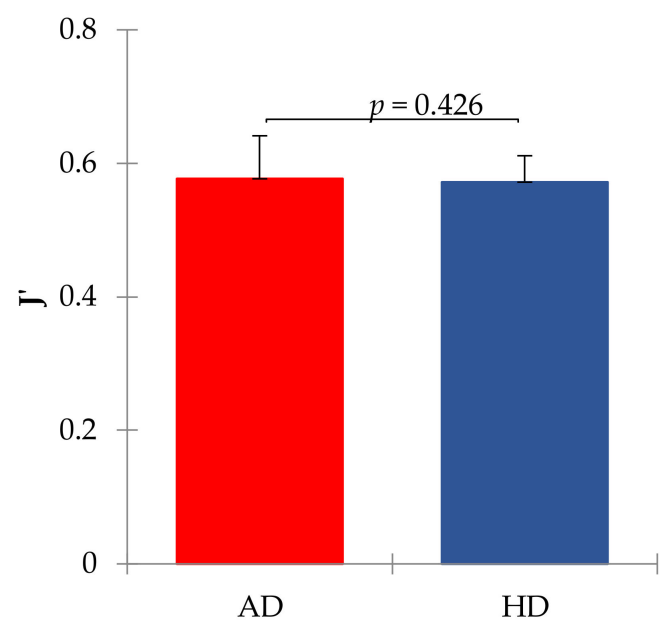

(B)

Figure 1. Shannon $\left(\mathrm{H}^{\prime}\right)$ and Evenness $\left(\mathrm{J}^{\prime}\right)$ indexes of diversity in arthritic (AD) and healthy (HD) dogs. Panel (A) shows mean values at the family level (means were significantly different for $p<0.05$ between $\mathrm{AD}$ and HD groups). Panel (B) shows mean values at the genus level (means were not significantly different between $\mathrm{AD}$ and HD groups). Shannon index was calculated according to the equation $\mathrm{H}^{\prime}=$ -sum $(\mathrm{Pi} \times \ln \mathrm{Pi})$, where $\mathrm{Pi}=$ frequency of every taxon within the sample. The evenness index was calculated as $\mathrm{J}^{\prime}=\mathrm{H}^{\prime} / \ln \mathrm{S}$, where $\mathrm{S}=$ total number of taxa within each sample. 


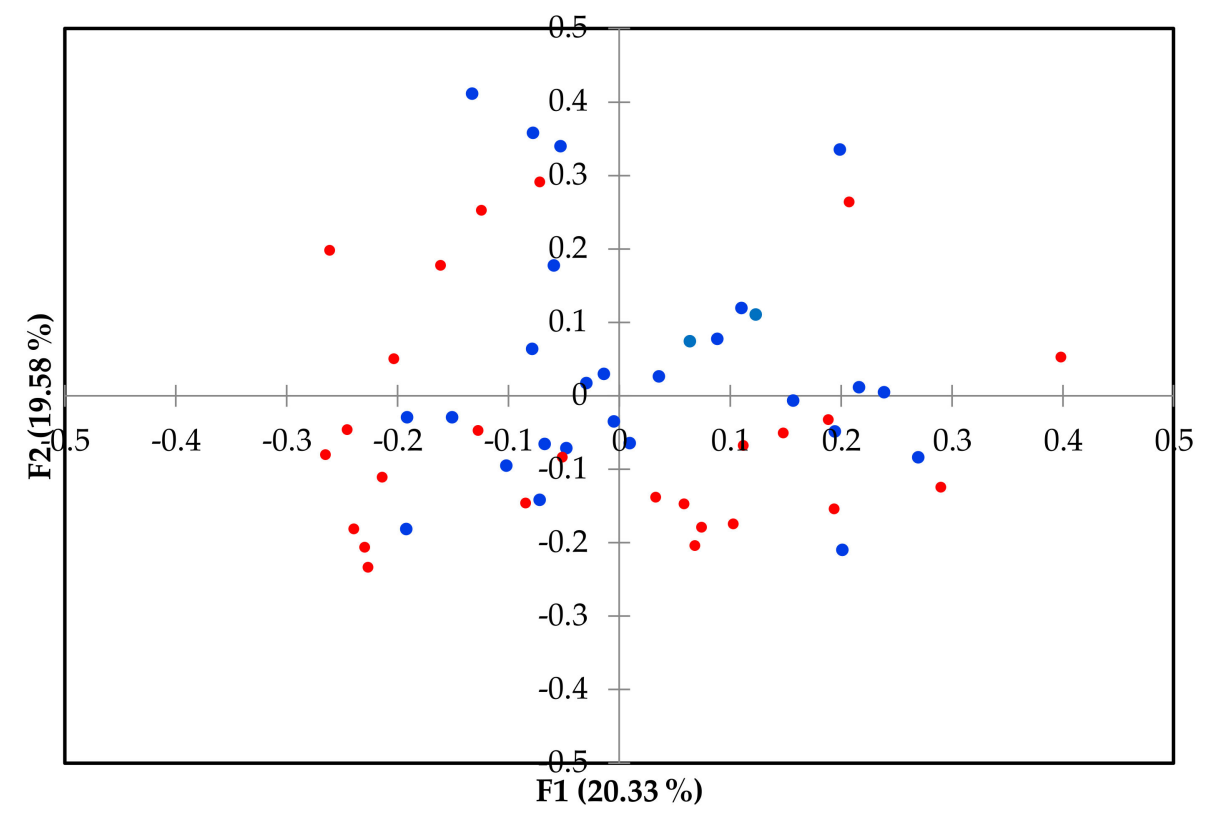

(A)

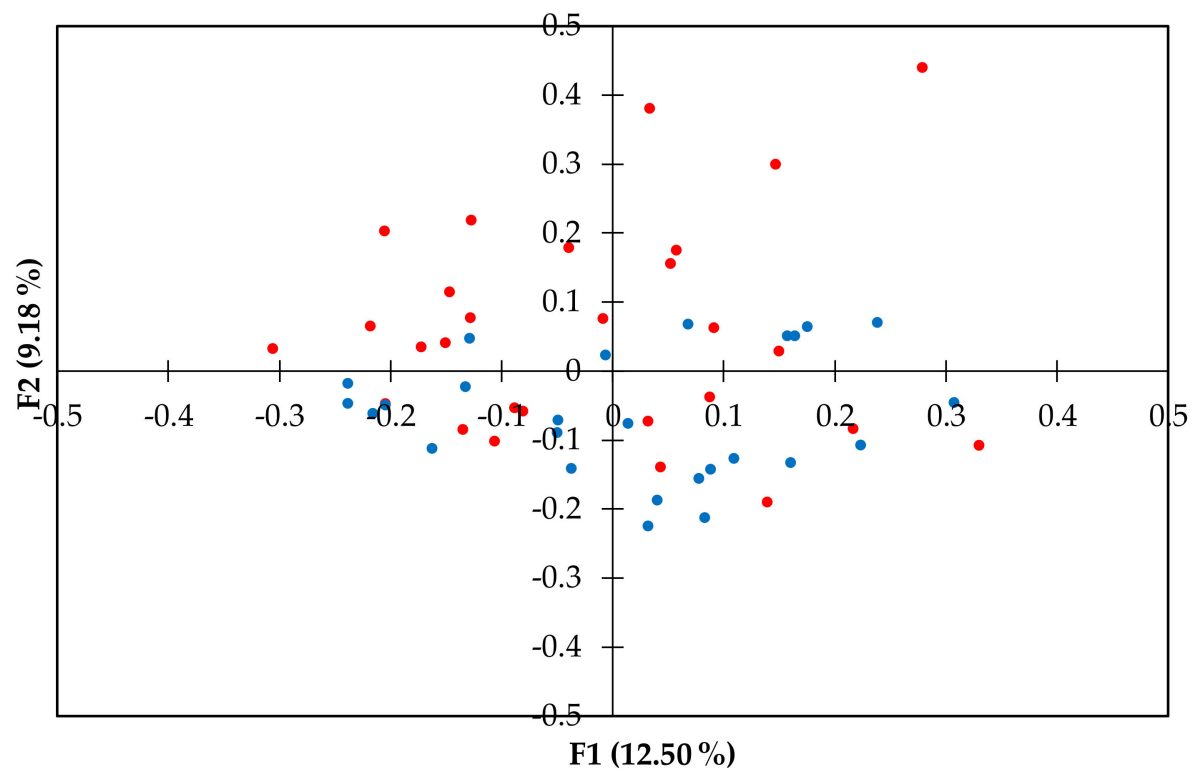

(B)

Figure 2. Principal coordinate (PCoA) plot representing the beta diversity of the microbial community among dogs' health status at family (A) and genus (B) level. PCoA was calculated using the Brain Curtis dissimilarity matrix. Dots in red represent arthritic dogs (AD), and dots in blue represent the healthy dogs (HD). The analysis of similarity (ANOSIM) was significant at the family level for $p<0.01$. 


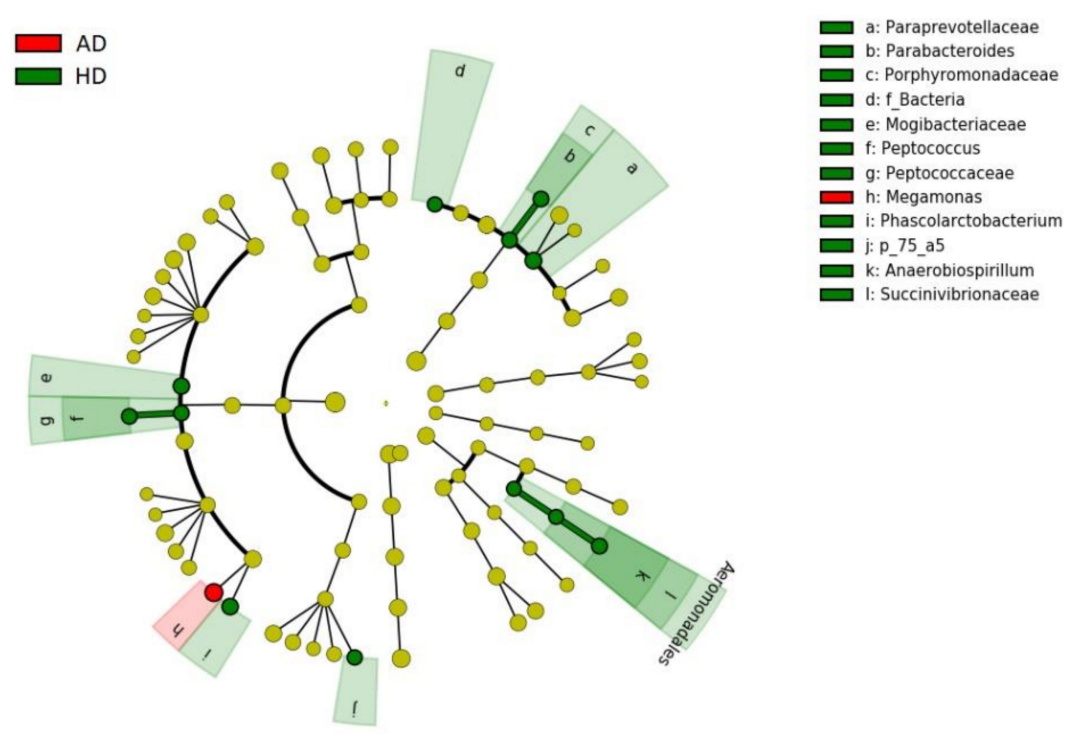

(A)

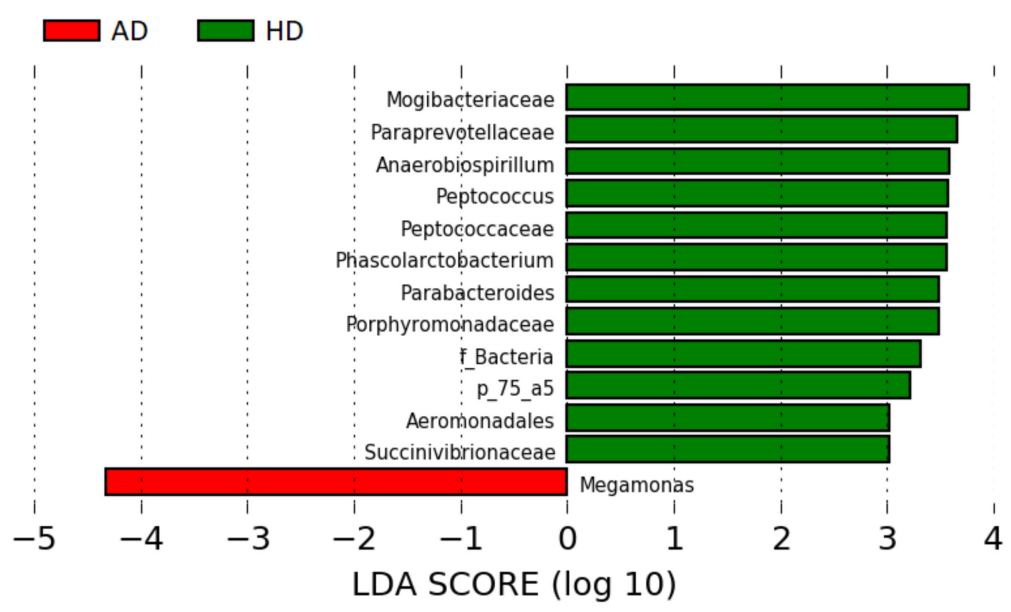

(B)

Figure 3. Bacterial taxa were significantly more abundant in the feces of healthy (HD) and arthritic dogs (AD). The cladogram (A) highlights impactful communities in individuals from each status, and (B) shows the score of the linear discriminant analysis (LDA, significant threshold $>2$ ).

\section{Discussion}

Osteoarthritis is a multifactorial and slowly progressive disease, resulting in a difficult early diagnosis through radiography or plasma biochemical analysis [23]. Different studies have revealed the relationship between cardiovascular disease, obesity, type 2 diabetes, and osteoarthritis, focusing on the role of the metabolic syndrome in provoking joint and bone damage [24,25].

Biochemical analyses of plasma are a suitable marker of inflammation (Table 1). CRP is a parameter of the acute phase of inflammation, and its detection in plasma could be useful in carrying information for the discrimination between suppurative arthritis and osteoarthritis in dogs, as demonstrated by Hillström et al. (2016) [26]. Rafiqul et al. (2006) [23] studied CRP concentration in dogs affected by stifle osteoarthritis and observed an increased concentration of CRP after 3, 6, and 9 months of experimental study. More recently, even Hindenberg et al. (2020) [27] focused on the significance of the concentration of high CRP $(>1 \mathrm{mg} / \mathrm{dL})$ in dogs. Classifying dogs in categories based on etiology and organ system affection, they found that the prevalent etiology was the inflammation (59\%), in which 
$51 \%$ was infectious, and interestingly, of this $51 \%$, the $38 \%$ had a bacterial origin. Instead, relying on the affected organs, aside from multiple organs and trauma (39 and 20\%, respectively), they detected an incidence of $14 \%$ for the gastrointestinal tract and $7 \%$ of the musculoskeletal system. Here, the AD group presented significantly higher values of CRP with respect to HD, and this could support that this parameter can be a marker of the arthritic process, including that of bacterial origin.

In this study, cholesterol significantly increased in $\mathrm{AD}$ at $\mathrm{T} 45$ when compared to HD, suggesting that an inflammation process was in the act. Rafiqul et al. (2006) [23] registered an increase in plasma cholesterol in dogs affected by stifle osteoarthritis. Cholesterol concentration has been reported to be an important biomarker of inflammation in obese dogs [28], mainly due to excess in the production of adipokines, which affects insulin resistance, and to the adipocyte secretions of inflammatory mediators, such as tumor necrosis factor (TNF), interleukin-6 (IL-6), and others, which contribute to systemic inflammation. Chronic low-grade systemic inflammation plays a fundamental role in the onset of several diseases in humans, such as coronary artery disease, insulin resistance, and metabolic syndrome [29-31]. A study on humans conducted by Farnaghi et al. (2017) [32] discovered that synovial fluid contains a low concentration of cholesterol compared to plasma levels, while the synovial fluid of osteoarthritic subjects has a higher amount of cholesterol and cholesterol crystals than healthy individuals. Furthermore, high plasma cholesterol can be found in overweight and obese dogs [33]. Since a correlation between gut dysbiosis and obesity/overweight has been reported [33,34], it is acceptable to assume that obesity conditions may be also related to other conditions of systemic inflammation, as arthritis.

ALP is a nonspecific phosphomonoesterase that hydrolyzes phosphate monoesters, and it is found attached to the plasma membrane, where extensive transport takes place [35]. ALP localized in the plasma membrane of the osteoblastic cells seems to have a specific role in bone mineralization [36], even if more pieces of evidence are needed to be found. ALP is found in many tissues, but especially in bones, liver, bile ducts, and in the gut epithelium, and an increase of this enzyme in plasma constitutes a biochemical marker of disease of these tissues; ALP is also used, together with epidemiologic, clinical, laboratory, and radiographic findings, to characterize polyarthritis in dogs [37]. In this study, we detected a significant decrease in ALP at T45, both in AD and more evidently in HD groups. Musco et al. (2019) [38], in a dietary intervention study on dogs affected by osteoarthritis, found lower ALP activity in the group receiving the prebiotic supplement than in sick dogs. In addition, mucosal expression, intestinal activity, and fecal concentration of ALP have been discovered to be lower in dogs with chronic inflammatory enteropathies [39], advising the use of this enzyme as a biomarker, also for enteropathies in dogs.

Cobalamin (vitamin B12) and folates (vitamin B9) detected in serum represent reliable functional biomarkers of intestinal permeability and malabsorption in dogs [40,41]. Cobalamin is absorbed only in the ileum, and its lower concentration is often associated with chronic intestinal pathologies in dogs [42-44], presumably manifested as small intestine malabsorption, secondary small intestine dysbiosis (extensive utilization of vitamin B12 by commensal bacteria), or both. Hypocobalaminemia is associated with lower serum albumin concentration [42] in the case of a gastrointestinal protein loss due to chronic intestinal inflammation $[45,46]$. However, in the present study, albumin concentration was higher in the $\mathrm{AD}$ group, although vitamin B12 was decreased; hence, it is not possible to attribute these changes to protein-losing enteropathy.

Folates are firstly absorbed in the duodenum and proximal jejunum as folate glutamate through B9 carriers, and they are principally produced by Bifidobacteria and Lactobacillus strains [47]. According to Heilmann et al. (2018) [44], hypofolatemia can derive from chronic malabsorption in the proximal small intestine of dogs, but at the same time, an increase or a normal concentration of vitamin $\mathrm{B} 9$ can be a symptom of a secondary small intestine dysbiosis, in which a high production of folates is made by resident microbiota or hypocobalaminemia [48]. Even Xu et al. (2016) [49] registered a decrease in serum folate in dogs affected by inflammatory bowel disease (IBD), together with lower cobalamin concentration. In this study, these parameters were sharply higher in HD group than in the AD group, 
both at $\mathrm{T} 0$ and T45, suggesting a healthier and more functional gut microbiome in the former dogs, able to supply the required amount of vitamins the organism needs. It is already evident the capacity of the gut population to synthesize the necessary elements to sustain the organism's homeostasis through the production of vitamins of the B group and secondary metabolites, such as SCFAs and lactic acid [50]. Dysregulation of this mechanism could compromise the mutualistic relationship among gut microbiome and host.

In regard to SCFAs, no particular variations were detected between the two groups, except for the molar proportion of butyrate that showed an increase in the AD group (Supplementary Table S2). The lack of substantial differences between the two groups in terms of SCFAs could be consequent to the rapid absorption of these metabolites, leaving a small but detectable concentration in feces. As already known, dogs do not utilize SCFAs as the principal source of energy, as ruminants do, but the dissimilarities, at least, indicate a variation in nutrient metabolism associated with a modification of gut microbiome.

Acetate, propionate, and butyrate exert beneficial effects on the homeostasis of metabolic functions since they have anti-inflammatory properties by controlling the development and modulating the immune system [51]. Besides the fact that butyrate is apported with the diet, this acid is mainly produced by the fermentation of the dietary fiber by Clostridial cluster IV and XIVa [52] in the gut lumen. Moreover, it acts through G protein-coupled receptor (GPCRs) pathway or by reducing histone deacetylases (HDACs) [53], involving the recruitment of macrophages and DCs to facilitate differentiation of T reg cells and immune-regulatory IL-10 [54]. Butyrate also supplies energy to the colonocytes, which means that a significant proportion of microbial-released butyrate is rapidly taken up and consumed locally [55], regulate host cell responses, and, for this reason, is considered to exert health-promoting effects on the colon [56]. Unexpectedly, our data indicated that the molar proportion of butyrate was higher in $\mathrm{AD}$, even though the mean values of butyrate proportion were numerically close between the two groups. This could be explained by the fact that arthritic dogs possess many butyrate producers, such as Megamonas genus, as registered in the study by Sandri et al. (2017) [17], and/or a relatively few bacterial butyrate-consumers. Moreover, since butyrate can even be synthesized from acetate and lactate from the interactions with the microbial ecosystem $[57,58]$, the increased butyrate in $\mathrm{AD}$ is likely due to this over synthesizing activity.

The reduction of alpha diversity indices (Figure 1), at least at the family taxonomic level, indicated that a dysbiosis probably occurred in the AD group, as supported by Minamoto et al. (2015) [59]. Furthermore, we also found differences in the relative abundances of bacterial taxa between AD and HD (Supplementary Tables S3 and S4) and beta diversity at the family level (Figure 2), suggesting a link between the microbiome and joint inflammation, even though no variation was observed at the genus level.

Although the markers of the leaky gut were not analyzed, the variation of the gut microbial community and the decrease of serum cobalamin and folates supported the hypothesis that a dysbiosis occurred. Several studies have investigated the modulation in gastrointestinal bacterial patterns and gut functional status in patients with arthritis. Ad exemplum, the study conducted by Muniz Pedrogo et al. (2019) [60] on humans reported an increased abundance of Clostridiaceae in both rheumatoid arthritis and IBD-associated arthropathy. Instead, Coulson et al. (2013) [61] found a high number of Bacteroides, Eubacterium (Collinsella aerofaciens), Lactobacillus, Bifidobacterium, Clostridium, Coliforms (Escherichia coli, Klebsiella pneumoniae), Enterococcus, Streptococcus, Staphylococcus, and Prevotella in patients with knee osteoarthritis. Wolfe et al. (2000) [62] reported that patients diagnosed with musculoskeletal diseases registered also common predispositions to dyspepsia, nausea, abdominal bloating, and irregular bowel habits. The interference of gut microbiota with bone metabolism has been postulated also in mice, in which a reduction of bone loss associated with ovariectomy has been reported after probiotic administration [63,64]. Even Mc Cabe et al. (2013) [65] found that the use of probiotic on male mice decreased intestinal inflammation and increased bone density. Another study on mice, supporting the relation among microbiome and arthritis, found that members of the genus 
Prevotella might influence bone loss by regulating the levels of SCFAs that mediate osteoclastogenesis in the host [66]. The differences of relative abundance of taxa in AD and HD groups found in tour study do not overlap with the previous researches, but it is legitimate to consider that a strict comparison of dogs' microbiome with humans and mice microbiome is not feasible due to the peculiar anatomy and physiology of these species, and then the observed differences were expected.

LEfSe analysis (Figure 3) revealed deep differences between the relative abundances of some taxa. Interestingly, we found a greater abundance of the genus Megamonas in AD, while the other genera were higher in HD. Other than butyrate, Megamonas is known to produce propionate, which has been shown to possess anti-inflammatory properties, and, additionally, this genus affects the metabolic rate of the host organism [67]. Here, the relative abundance of Megamonas in AD was 2-fold higher than that of the HD group and vice versa, while Phascolarctobacterium was 2-fold lower. It seemed that a shift from Megamonas with the Phascolarctobacterium occurred in AD and HD microbiome since these taxa belong to the same family of Veilloneaceae. Similar results have also been observed in human studies [68,69], suggesting that these two genera occupy the same ecological niche and compete for the same substrates. On the other hand, it should be considered that data refer to relative abundances, meaning that the increase of Megamonas might be due to a decrease of other genera and so do not necessarily reflect a higher amount of this genus in the microbial population of arthritic dogs.

We also detected, in HD group, a higher abundance of bacterial members of the Clostridiales order (Mogibacteriaceae, Peptococcaceae along with Peptococcus genus and Phascolarctobacterium genus) and in Erysipelotricaceae ( $p \_75 \_a 5$ genus), sharing the same Firmicutes phylum. Clostridiales plays a crucial role in preventing leaky gut syndrome, which occurs when gut barrier permeability is altered, prompting excessive inflammation [70]. Similar results were found in a study on dogs conducted by Minamoto et al. (2015) [59], in which Erysipelotricaceae, Clostridiales, and Bacteroidetes were underrepresented in dogs with IBD. Even members of the Bacteroidales order (Paraprevotellaceae, Porphyromonadaceae, and genus Parabacteroides) showed a higher abundance in HD. On the contrary, Omori et al. (2017) [71] found a great abundance of Paraprevotellaceae and Porphyromonas genus in dogs affected by IBD. The presence of the Parabacteroides genus in humans is thought to help to prevent the invasion and colonization of pathogens by secreting bacteriocins that are toxic to other strains of bacteria [72]. Individuals with IBD often lack a population of Parabacteroides in their gut, suggesting that this genus also helps protect against excessive inflammation [72]. Unexpectedly, Aeromonadales-the relative belonging family Succinivibionaceae and the relative genus Anaerobiumspirillum-were higher in healthy dogs. These bacteria belong to the Proteobacteria phylum, which has been associated with IBD [59-73], even if Anaerobiospirillum is commonly found in feces of healthy dogs [74].

Definitively, the lesson to get from these results is that gut microbiome is a complex ecosystem, and thus the variation in the composition of the microbiome as a whole, rather than to the variation of the single taxon, can better depict the effect of an inferred factor in gut-host microbiota interaction.

The modulation of the gut microbiome by arthritis risk factors (e.g., diet, obesity, age, physical exercise, sex, genetic factors, and immunity activation) could alter the intestinal thigh junctions, allowing the crossing of the local bacteria by the DCs and macrophages, which eventually can reach tissue or organs through the bloodstream, causing an inflammatory response in the host [6]. It can be argued that the gut is a source of these microorganisms because altered gut permeability has been observed in individuals with arthritis [75,76]; therefore, some living bacteria could be transferred from the gut to the joints through the circulatory or lymphatic system [77]. The existence of this axis in dogs deserves further investigations to be better understood.

\section{Conclusions}

The gut microbiome is strictly related to several forms of pathologies. In the present study, we analyzed the variation of the gut microbial community in arthritic dogs, and the results obtained suggested that it might influence the degeneration of joints and bones through the propagation of systemic inflammation. Despite our findings on bacterial taxa of dog microbiome were not similar to 
those detected in other studies, we hypothesized that a large inter-individual variability among dogs exists and that different bacterial strains could contribute in a unique way to modify the inflammatory status of the subjects. Hence, it is not possible to attribute a beneficial or harmful role to a single taxon in arthritic disease but is likely that a variation of the total genera composing microbiome could reshape the entire physiology of the host.

Supplementary Materials: The following are available online at http://www.mdpi.com/2306-7381/7/3/92/s1, Table S1: Health status, kind of breed, sex, weight, and age of the dogs recruited for the study; Table S2: Mean concentrations $(\mu \mathrm{mol} / \mathrm{g})$ and molar proportions $(\%)$ of lactate and short-chain fatty acids in the feces of the dogs sampled at the beginning of the study (T0) and after 45 (T45) days; Table S3: Relative abundances of the prevalent families detected in dog feces samples at the beginning of the study (T0) and the end (T45); Table S4: Relative abundances of the prevalent genera detected in dog feces samples at the beginning of the study (T0) and the end (T45).

Author Contributions: Conceptualization, B.S. and M.S.; methodology, M.C. and E.S.; software, E.S.; formal analysis, M.C. and E.S.; investigation, B.S., S.S., and M.S.; data curation, S.S. and M.S.; writing-original draft preparation, M.C. and B.S.; writing-review and editing, all; supervision, B.S.; funding acquisition, B.S. All authors have read and agreed to the published version of the manuscript.

Funding: The study was supported financially by the Department of Agricultural, Food, Environmental, and Animal Sciences, University of Udine.

Acknowledgments: We thank the Animal Care veterinary clinic, Martignacco (Udine, Italy) for providing samples and diagnosis of the dogs and the N.P. Industries for providing complete diets.

Conflicts of Interest: The authors declare no conflict of interest.

\section{References}

1. Suchodolski, J.S.; Markel, M.E.; Garcia-Mazcorro, J.F.; Unterer, S.; Heilmann, R.M.; Dowd, S.E.; Kachroo, P.; Ivanov, I.; Minamoto, Y.; Dillman, E.M.; et al. The fecal microbiome in dogs with acute diarrhea and idiopathic inflammatory bowel disease. PLoS ONE 2012, 7, e51907. [CrossRef]

2. Al Shawaqfeh, M.K.; Wajid, B.; Minamoto, Y.; Markel, M.; Lidbury, J.A.; Steiner, J.M.; Serpedin, E.; Suchodolski, J.S. A dysbiosis index to assess microbial changes in fecal samples of dogs with chronic inflammatory enteropathy. FEMS Microbiol. Ecol. 2017, 93. [CrossRef]

3. Szychlinska, M.A.; Di Rosa, M.; Castorina, A.; Mobasheri, A.; Musumeci, G. A correlation between intestinal microbiota dysbiosis and osteoarthritis. Heliyon 2019, 5, e01134. [CrossRef] [PubMed]

4. O'Mahony, S.M.; Clarke, G.; Borre, Y.E.; Dinan, T.G.; Cryan, J.F. Serotonin, tryptophan metabolism and the brain-gut-microbiome axis. Behav. Brain Res. 2015, 277, 32-48. [CrossRef]

5. Scarsella, E.; Cintio, M.; Iacumin, L.; Ginaldi, F.; Stefanon, B. Interplay between neuroendocrine biomarkers and gut microbiota in dogs supplemented with grape proanthocyanidins: Results of dietary intervention study. Animals 2020, 10, 531. [CrossRef] [PubMed]

6. Hernandez, C.J. The Microbiome and Bone and Joint Disease. Curr. Rheumatol. Rep. 2018, 19, 77. [CrossRef]

7. Hernandez, C.J.; Guss, J.D.; Luna, M.; Goldring, S.R. Links between the Microbiome and Bone. J. Bone Miner. Res. 2016, 31, 1638-1646. [CrossRef]

8. Quach, D.; Britton, R.A. Gut microbiota and bone health. Understanding the gut-bone signaling axis. Adv. Exp. Med. Biol. 2017, 1033, 47-58.

9. Berthelot, J.M.; Wendling, D. Translocation of dead or alive bacteria from mucosa to joints and epiphyseal bone-marrow: Facts and hypotheses. Jt. Bone Spine 2020, 87, 31-36. [CrossRef]

10. Korotkyi, O.; Kyriachenko, Y.; Kobyliak, N.; Falalyeyeva, T.; Ostapchenko, L. Crosstalk between gut microbiota and osteoarthritis: A critical view. J. Funct. Foods 2020, 68, 103904. [CrossRef]

11. Tomasello, G.; Tralongo, P.; Damiani, P.; Sinagra, E.; Di Trapani, B.; Zeenny, M.N.; Hussein, I.H.; Jurjus, A.; Leone, A. Dismicrobism in inflammatory bowel disease and colorectal cancer: Changes in response of colocytes. World J. Gastroenterol. 2014, 20, 18121-18130. [CrossRef] [PubMed]

12. Rodríguez, J.M. The origin of human milk bacteria: Is there a bacterial entero-mammary pathway during late pregnancy and lactation? Adv. Nutr. 2014, 5, 779-784. [CrossRef] 
13. Ayral, X.; Pickering, E.H.; Woodworth, T.G.; Mackillop, N.; Dougados, M. Synovitis: A potential predictive factor of structural progression of medial tibiofemoral knee osteoarthritis-results of a 1 year longitudinal arthroscopic study in 422 patients. Osteoarthr. Cartil. 2005, 13, 361-367. [CrossRef] [PubMed]

14. Dahaghin, S.; Bierma-Zeinstra, S.M.A.; Koes, B.W.; Hazes, J.M.W.; Pols, H.A.P. Do metabolic factors add to the effect of overweight on hand osteoarthritis? The Rotterdam Study. Ann. Rheum. Dis. 2007, 66, 916-920. [CrossRef] [PubMed]

15. Kraus, V.B.; McDaniel, G.; Huebner, J.L.; Stabler, T.V.; Pieper, C.F.; Shipes, S.W.; Petry, N.A.; Low, P.S.; Shen, J.; McNearney, T.A.; et al. Direct in vivo evidence of activated macrophages in human osteoarthritis. Osteoarthr. Cartil. 2016, 24, 1613-1621. [CrossRef] [PubMed]

16. Jubair, W.K.; Hendrickson, J.D.; Severs, E.L.; Schulz, H.M.; Adhikari, S.; Ir, D.; Pagan, J.D.; Anthony, R.M.; Robertson, C.E.; Frank, D.N.; et al. Modulation of inflammatory arthritis in mice by gut microbiota through mucosal inflammation and autoantibody generation. Arthritis Rheumatol. 2018, 70, 1220-1233. [CrossRef]

17. Sandri, M.; Dal Monego, S.; Conte, G.; Sgorlon, S.; Stefanon, B. Raw meat-based diet influences faecal microbiome and end products of fermentation in healthy dogs. BMC Vet. Res. 2017, 13, 65. [CrossRef]

18. Klindworth, A.; Pruesse, E.; Schweer, T.; Peplies, J.; Quast, C.; Horn, M.; Glockner, F.O. Evaluation of general $16 \mathrm{~S}$ ribosomal RNA gene PCR primers for classical and next-generation sequencing-based diversity studies. Nucleic Acids Res. 2013, 41, e1. [CrossRef]

19. Bolyen, E.; Rideout, J.R.; Dillon, M.R.; Bokulich, N.A.; Abnet, C.C.; Al-Ghalith, G.A.; Alexander, H.; Alm, E.J.; Arumugam, M.; Asnicar, F.; et al. Reproducible, interactive, scalable and extensible microbiome data science using QIIME 2. Nat. Biotechnol. 2019, 37, 852-857. [CrossRef]

20. Sandri, M.; Sgorlon, S.; Scarsella, E.; Stefanon, B. Effect of different starch sources in a raw meat-based diet on fecal microbiome in dogs housed in a shelter. Anim. Nutr. J. 2020. [CrossRef]

21. Addinsoft. XLSTAT Statistical and Data Analysis Solution; Addinsoft: Boston, MA, USA, 2020.

22. Segata, N.; Izard, J.; Waldron, L.; Gevers, D.; Miropolsky, L.; Garrett, W.S.; Huttenhower, C. Metagenomic biomarker discovery and explanation. Genome Biol. 2011, 12, R60. [CrossRef] [PubMed]

23. Alam, M.R.; Lee, H.B.; Park, S.Y.; Lee, H.Y.; Kim, I.S.; Kang, H.S.; Kim, N.S. Changes in the haematobiochemical parameters in experimental stifle osteoarthritis in dogs. Pak. J. Biol. Sci. 2006, 9, 2869-2874.

24. Hotamisligil, G.S.; Erbay, E. Nutrient sensing and inflammation in metabolic diseases. Nat. Rev. Immunol. 2008, 8, 923-934. [CrossRef] [PubMed]

25. Barna, I.; Nyúl, D.; Szentes, T.; Schwab, R. Review of the relation between gut microbiome, metabolic disease and hypertension. Orv. Hetil. 2018, 159, 346-351. [CrossRef]

26. Hillström, A.; Bylin, J.; Hagman, R.; Björhall, K.; Tvedten, H.; Königsson, K.; Fall, T.; Kjelgaard-Hansen, M. Measurement of serum C-reactive protein concentration for discriminating between suppurative arthritis and osteoarthritis in dogs. BMC Vet. Res. 2016, 12, 240. [CrossRef] [PubMed]

27. Hindenberg, S.; Bauer, N.; Moritz, A. Extremely high canine C-reactive protein concentrations $>100$ $\mathrm{mg} / \mathrm{L}$ - prevalence, etiology and prognostic significance. BMC Vet. Res. 2020, 16, 147. [CrossRef]

28. Eirmann, L.A.; Freeman, L.M.; Laflamme, D.P.; Michel, K.E.; Satyaraj, E. Comparison of adipokine concentrations and markers of inflammation in obese versus lean dogs. Int. J. Appl. Res. Vet. Med. 2009, 7, 196-205.

29. Yudkinm, J.; Kamari, M.; Humphries, S.; Mohamed-Ali, V. Inflammation, obesity, stress and coronary heart disease: Is interleukin-6 the link? Atherosclerosis 2000, 148, 209-241. [CrossRef]

30. Dandona, P.; Aljada, A.; Chaudhuri, A.; Mohanty, P.; Garg, R. Metabolic syndrome: A comprehensive perspective based on interactions between obesity, diabetes, and inflammation. Circulation 2005, 111, 1448-1454. [CrossRef]

31. Fantuzzi, G. Adipose in the regulation of inflammation. Immunol. Endocr. Metab. Agents Med. Chem. 2007, 7, 129-136. [CrossRef]

32. Farnaghi, S.; Crawford, R.; Xiao, Y.; Prasadam, I. Cholesterol metabolism in pathogenesis of osteoarthritis disease. Int. J. Rheum. Dis. 2017, 20, 131-140. [CrossRef] [PubMed]

33. Park, H.J.; Lee, S.E.; Oh, J.H.; Seo, K.W.; Song, K.H. Leptin, adiponectin and serotonin levels in lean and obese dogs. BMC Vet. Res. 2014, 10, 113. [CrossRef] [PubMed]

34. Maslowski, K.M.; Vieira, A.T.; Ng, A.; Kranich, J.; Sierro, F.; Yu, D.; Schilter, H.C.; Rolph, M.S.; Mackay, F.; Artis, D.; et al. Regulation of inflammatory responses by gut microbiota and chemoattractant receptor GPR43. Nature 2009, 461, 1282-1286. [CrossRef] [PubMed] 
35. Kim, E.K.; Wyckoff, H.W. Structure and function of alkaline phosphatases. Clin. Chim. Acta 1990, 186, 175-187. [CrossRef]

36. Rodan, G.A.; Rodan, S.B. Expression of the osteoblastic phenotype. Bone Miner. Res. 1983, 2, $244-245$.

37. Jacques, D.; Cauzinille, L.; Bouvy, B.; Dupre, G. A retrospective study of 40 dogs with polyarthritis. Vet. Surg. 2002, 31, 428-434. [CrossRef] [PubMed]

38. Musco, N.; Vassalotti, G.; Mastellone, V.; Cortese, L.; della Rocca, G.; Molinari, M.L.; Calabrò, S.; Tudisco, R.; Cutrignelli, M.I.; Lombardi, P. Effects of a nutritional supplement in dogs affected by osteoarthritis. Vet. Med. Sci. 2019, 5, 325-335. [CrossRef]

39. Ide, K.; Kato, K.; Sawa, Y.; Hayashi, A.; Takizawa, R.; Nishifuji, K. Comparison of the expression, activity, and fecal concentration of intestinal alkaline phosphatase between healthy dogs and dogs with chronic enteropathy. Am. J. Vet. Res. 2016, 77, 721-729. [CrossRef]

40. Batt, R.M.; Morgan, J.O. Role of Serum Folate and Vitamin B12 Concentrations in the Differentiation of Small Intestinal Abnormalities in the Dog. Res. Vet. Sci. 1982, 32, 17-22. [CrossRef]

41. Heilmann, R.M.; Steiner, J.M. Clinical utility of currently available biomarkers in inflammatory enteropathies of dogs. J. Vet. Intern. Med. 2018, 32, 1495-1508. [CrossRef]

42. Allenspach, K.; Wieland, B.; Gröne, A.; Gaschen, F. Chronic enteropathies in dogs: Evaluation of risk factors for negative outcome. J. Vet. Intern. Med. 2007, 21, 700-708. [CrossRef] [PubMed]

43. Berghoff, N.; Parnell, N.K.; Hill, S.L.; Suchodolski, J.S.; Steiner, J.M. Serum cobalamin and methylmalonic acid concentrations in dogs with chronic gastrointestinal disease. Am. J. Vet. Res. 2013, 74, 84-89. [CrossRef] [PubMed]

44. Heilmann, R.M.; Berghoff, N.; Mansell, J.; Grützner, N.; Parnell, N.K.; Gurtner, C.; Suchodolski, J.S.; Steiner, J.M. Association of fecal calprotectin concentrations with disease severity, response to treatment, and other biomarkers in dogs with chronic inflammatory enteropathies. J. Vet. Intern. Med. 2018, 32, 679-692. [CrossRef] [PubMed]

45. Dossin, O.; Lavoué, R. Protein-losing enteropathies in dogs. Vet. Clin. N. Am. Small Anim. Pract. 2011, 41, 399-418. [CrossRef]

46. Wennogle, S.A.; Priestnall, S.L.; Webb, C.B. Histopathologic characteristics of intestinal biopsy samples from dogs with chronic inflammatory enteropathy with and without hypoalbuminemia. J. Vet. Intern. Med. 2017, 31, 371-376. [CrossRef]

47. LeBlanc, J.G.; Milani, C.; de Giori, G.S.; Sesma, F.; van Sinderen, D.; Ventura, M. Bacteria as vitamin suppliers to their host: A gut microbiota perspective. Curr. Opin. Biotechnol. 2013, 24, 160-168. [CrossRef]

48. Ruaux, C.G. Laboratory testing for the diagnosis of intestinal disorders. In Small Animal Gastroenterology; Steiner, J.M., Ed.; Schlütersche: Hannover, Germany, 2008; pp. 50-55.

49. Xu, J.; Verbrugghe, A.; Lourenço, M.; Janssens, G.P.; Liu, D.J.; Van de Wiele, T.; Eeckhaut, V.; Van Immerseel, F.; Van de Maele, I.; Niu, Y.; et al. Does canine inflammatory bowel disease influence gut microbial profile and host metabolism? BMC Vet. Res. 2016, 12, 114. [CrossRef]

50. Murugesan, S.; Nirmalkar, K.; Hoyo-Vadillo, C.; García-Espitia, M.; Ramírez-Sanchez, D.; García-Mena, J. Gut microbiome production of short chain fatty acids and obesity in children. Eur. J. Clin. Microbiol. Infect. Dis. 2018, 37, 621-625. [CrossRef]

51. Macia, L.; Thorburn, A.N.; Binge, L.C.; Marino, E.; Rogers, K.E.; Maslowski, K.M.; Mackay, C.R. Microbial influences on epithelial integrity and immune function as a basis for inflammatory diseases. Immunol. Rev. 2012, 245, 164-176. [CrossRef]

52. Li, R.W.; Li, C.-J. Enhancing butyrate biosynthesis in the gut for health benefits. In Butyrate: Food Sources, Functions and Health Benefits; Li, C.-J., Ed.; Nova Science Publishers, Inc.: New York, NY, USA, 2014.

53. Stilling, R.M.; van de Wouw, M.; Clarke, G.; Stanton, C.; Dinan, T.G.; Cryan, J.F. The neuropharmacology of butyrate: The bread and butter of the microbiota-gut-brain axis? Neurochem. Int. 2016, 99, 110-132. [CrossRef]

54. Singh, N.; Gurav, A.; Sivaprakasam, S.; Brady, E.; Padia, R.; Shi, H.; Ganapathy, V. Activation of Gpr109a, receptor for niacin and the commensal metabolite butyrate, suppresses colonic inflammation and carcinogenesis. Immunity 2014, 40, 128-139. [CrossRef] [PubMed]

55. Hamer, H.M.; Jonkers, D.; Venema, K.; Vanhoutvin, S.; Troost, F.J.; Brummer, R.-J. The role of butyrate on colonic function. Aliment. Pharmacol. Ther. 2008, 27, 104-119. [CrossRef] [PubMed] 
56. Louis, P.; Young, P.; Holtrop, G.; Flint, H.J. Diversity of human colonic butyrate-producing bacteria revealed by analysis of the butyryl-CoA:acetate CoA-transferase gene. Environ. Microbiol. 2010, 12, 304-314. [CrossRef]

57. Duncan, S.H.; Holtrop, G.; Lobley, G.E.; Calder, A.G.; Stewart, C.S.; Flint, H.J. Contribution of acetate to butyrate formation by human faecal bacteria. Br. J. Nutr. 2004, 91, 915-923. [CrossRef] [PubMed]

58. Duncan, S.H.; Louis, P.; Flint, H.J. Lactate-utilizing bacteria, isolated from human feces, that produce butyrate as a major fermentation product. Appl. Environ. Microbiol. 2004, 70, 5810-5817. [CrossRef]

59. Minamoto, Y.; Otoni, C.C.; Steelman, S.M.; Büyükleblebici, O.; Steiner, J.M.; Jergens, A.E.; Suchodolski, J.S. Alteration of the fecal microbiota and serum metabolite profiles in dogs with idiopathic inflammatory bowel disease. Gut Microbes 2015, 6, 33-47. [CrossRef]

60. Muñiz Pedrogo, D.A.; Chen, J.; Hillmann, B.; Jeraldo, P.; Al-Ghalith, G.; Taneja, V.; Davis, J.M.; Knights, D.; Nelson, H.; Faubion, W.A.; et al. An increased abundance of Clostridiaceae characterizes arthritis in inflammatory bowel disease and rheumatoid arthritis: A cross-sectional study. Inflamm. Bowel Dis. 2019, 25, 902-913. [CrossRef]

61. Coulson, S.; Butt, H.; Vecchio, P.; Gramotnev, H.; Vitetta, L. Green-lipped mussel extract (Perna canaliculus) and glucosamine sulphate in patients with knee osteoarthritis: Therapeutic efficacy and effects on gastrointestinal microbiota profiles. Inflammopharmacology 2013, 21, 79-90. [CrossRef]

62. Wolfe, F.; Kong, S.X.; Watson, D.J. Gastrointestinal symptoms and health related quality of life in patients with arthritis. J. Rheumatol. 2000, 27, 1373-1378.

63. Britton, R.A.; Irwin, R.; Quach, D.; Schaefer, L.; Zhang, J.; Lee, T.; Mccabe, L.R. Probiotic L. reuteri treatment prevents bone loss in a menopausal ovariectomized mouse model. J. Cell. Phys. 2014, 229, 1822-1830. [CrossRef]

64. Li, Y.; Xiao, W.; Luo, W.; Zeng, C.; Deng, Z.; Ren, W.; Wu, G.; Lei, G. Alterations of amino acid metabolism in osteoarthritis: Its implications for nutrition and health. Amino Acids 2016, 48, 907-914. [CrossRef]

65. McCabe, L.R.; Irwin, R.; Schaefer, L.; Britton, R.A. Probiotic use decreases intestinal inflammation and increases bone density in healthy male but not female mice. J. Cell. Phys. 2013, 228, 1793-1798. [CrossRef] [PubMed]

66. Lucas, S.; Omata, Y.; Hofmann, J.; Böttcher, M.; Iljazovic, A.; Sarter, K.; Albrecht, O.; Schulz, O.; Krishnacoumar, B.; Krönke, G.; et al. Short-chain fatty acids regulate systemic bone mass and protect from pathological bone loss. Nat. Commun. 2018, 9, 55. [CrossRef] [PubMed]

67. Kieler, I.N.; Shamzir Kamal, S.; Vitger, A.D.; Nielsen, D.S.; Lauridsen, C.; Bjornvad, C.R. Gut microbiota composition may relate to weight loss rate in obese pet dogs. Vet. Med. Sci. 2017, 3, 252-262. [CrossRef] [PubMed]

68. Xie, M.; Chen, G.; Wan, P.; Dai, Z.; Hu, B.; Chen, L.; Ou, S.; Zeng, X.; Sun, Y. Modulating effects of dicaffeoylquinic acids from Ilex kudingcha on intestinal microecology in vitro. J. Agric. Food Chem. 2017, 65, 10185-10196. [CrossRef] [PubMed]

69. Geng, H.; Shu, S.; Dong, J.; Li, H.; Xu, C.; Han, Y.; Hu, J.; Han, Y.; Yang, R.; Cheng, N. Association study of gut flora in Wilson's disease through high-throughput sequencing. Medicine 2018, 97, e11743. [CrossRef] [PubMed]

70. Suchodolski, J.S.; Dowd, S.E.; Wilke, V.; Steiner, J.M.; Jergens, A.E. $16 S$ rRNA gene pyrosequencing reveals bacterial dysbiosis in the duodenum of dogs with idiopathic inflammatory bowel disease. PLoS ONE 2012, 7, e39333. [CrossRef]

71. Omori, M.; Maeda, S.; Igarashi, H.; Ohno, K.; Sakai, K.; Yonezawa, T.; Horigome, A.; Odamaki, T.; Matsuki, N. Fecal microbiome in dogs with inflammatory bowel disease and intestinal lymphoma. J. Vet. Med. Sci. 2017, 79, 1840-1847. [CrossRef]

72. Nakano, V.; Ignacio, A.; Fernandes, M.R.; Fukugaiti, M.H.; Avila-Campos, M.J. Intestinal Bacteroides and Parabacteroides species producing antagonistic substances. Microbiology 2006, 1, 61-64.

73. Mukhopadhya, I.; Hansen, R.; El-Omar, E.M.; Hold, G.L. IBD-what role do Proteobacteria play? Nat. Rev. Gastroenterol. Hepatol. 2012, 9, 219-230. [CrossRef]

74. Malnick, H.; Williams, K.; Phil-Ebosie, J.; Levy, A.S. Description of a medium for isolating Anaerobiospirillum spp., a possible cause of zoonotic disease, from diarrheal feces and blood of humans and use of the medium in a survey of human, canine, and feline feces. J. Clin. Microbiol. 1990, 28, 1380-1384. [CrossRef] [PubMed] 
75. Kempsell, K.E.; Cox, C.J.; Hurle, M.; Wong, A.; Wilkie, S.; Zanders, E.D.; Gaston, J.S.; Crowe, J.S. Reverse transcriptase-PCR analysis of bacterial rRNA for detection and characterization of bacterial species in arthritis synovial tissue. Infect. Immun. 2000, 68, 6012-6026. [CrossRef] [PubMed]

76. Katz, K.D.; Hollander, D. Intestinal mucosal permeability and rheumatological diseases. Bailliere's Clin. Rheumatol. 1989, 3, 271-284. [CrossRef]

77. Berthelot, J.M.; Claudepierre, P. Trafficking of antigens from gut to sacroiliac joints and spine in reactive arthritis and spondyloarthropathies: Mainly through lymphatics? Jt. Bone Spine 2016, 83, 485-490. [CrossRef] [PubMed]

(C) 2020 by the authors. Licensee MDPI, Basel, Switzerland. This article is an open access article distributed under the terms and conditions of the Creative Commons Attribution (CC BY) license (http://creativecommons.org/licenses/by/4.0/). 